\title{
Speech methods of representation of scientific knowledge as a tool for increasing reader interest to popular science texts (based on the material of online versions of journals)
}

\author{
Yana Kosyakova ${ }^{*}$ \\ ${ }^{1}$ Don State Technical University, Gagarina sq., 1, Rostov on Don, 344003, Russia
}

\begin{abstract}
The purpose of this work is to: 1) identify, study and analyze speech methods of updating scientific knowledge as a tool for influencing the reader's consciousness; 2) identify potential criteria for increasing the audience's interest in the presented scientific knowledge in the aspect of popular science discourse on the example of popular science articles from selected journals for analysis; 3 ) describe the influencing potential of these speech methods of presenting knowledge to the addressee. Methodology. The influencing potential of media sources that increase the interest of the readership is revealed through a series of studies describing the factors and methods of popularizing scientific knowledge in modern media on the basis of intersecting discourses (social-political, pedagogical, medical, etc.). The research is also based on the method of continuous sampling in the selection of practical material, the method of quantitative and qualitative analysis. The article substantiates the most effective and frequent speech patterns.
\end{abstract}

\section{Introduction}

In the era of information technology and the Internet, the share of "screen consumption" has increased significantly. Mass communications have undergone significant changes in the media sphere, which has led to digital globalization and the emergence of faster, more open, active and competitive media [1]. In the context of modern convergent journalism, it is not enough to provide online access to a digital archive (many Russian journals have an online version) in order to expand the capabilities of print media and gain the attention of a wide range of readers in socio-political, medical, and pedagogical discourse [2-6]. In particular, popular science discourse is no exception. There was a need to review the verbal ways of presenting information, in particular scientific facts, and consider them as a tool to increase the reader's interest in scientific knowledge within the framework of popular science discourse. This fact largely determines the solution of a number of key issues within the framework of the linguodidactic direction, such as: the quality of reading, understanding of the text, creating an attractive text for a wide consumer audience. Thus,

\footnotetext{
* Corresponding author: Yask_2018@mail.ru
} 
the quality of reading largely implies the formation of a" literate reader", that is, a reader who not only acquires reading experience, but also learns and uses information obtained from media sources.

So, four academic groups of the technical direction (of different specialization/orientation) were offered articles from the popular scientific journals "Quantum" (mostly physical and mathematical), "Machines and Mechanisms" (for a wider audience, since the intra-scientific and international component is well represented), "Sky" (for astronomy lovers), "Dilettante" (a historical magazine for the whole family). 82 respondents took part in the survey. Students were introduced to the electronic format of popular science magazines. The criteria for evaluation were (according to a five-point scale): informative content/ knowledge-intensive content of the proposed material; dialogic narration; relevance of the submitted material, focus on a wide and enthusiastic audience; application of the "hook" technique in the lead paragraph; clarification/ explanation, explanation, paraphrasing, in some cases metaphorization of scientific language. Respondents were also asked to refine the list of evaluation criteria: to offer their own, which, in their opinion, were significant, but are not represented in this list of the survey.

The result of the survey showed that information content was one of the most important criteria for $76 \%$ of the surveyed students, who highly appreciated the knowledge-intensive indicator of the media sources "Quantum", "Machines and Mechanisms". Moreover, according to the majority of respondents, it is easier for them to perceive information presented by simple or complex non-union constructions; for $81 \%$ of students, the dialogic nature of the narrative was important, that is, the respondents were impressed by the constant presence of the author-scientist/ author-journalist, which supported their interest and motivated them to further read the material. This indicator was presented in all the studied journals, but the highest percentage was found in the journal "Sky". The criterion of updating knowledge, the presence of an explanatory type of narrative was attractive for $96 \%$ of respondents. The criterion of "hook", that is, the presence of a lead paragraph, and attention retention was noted by $91 \%$ of respondents. This rhetorical technique allowed students to understand in a few key lines how interesting the material is to them and whether there is a desire to read it in full. In addition, as a rule, in the lead paragraph there are key words-markers, which are, in a way, hooks of the reader's attention. This survey showed that the dialogic nature of the narrative, the "hook" of the reader's attention, the actualization of knowledge, the explanatory type of the narrative become key factors when choosing a media source by the readership, and here the scientific nature of the presented material plays an important role - it is important for readers not only to receive facts, but to receive them in a "scientific form". The survey data are presented in Table 1.

It is this factor that determines the formation of a" literate reader " who participates in the dialogue as a full-fledged reader-researcher/ reader-scientist. The obtained data in many respects prompted the consideration of the question of speech techniques, strategies, methods of presenting scientific knowledge to a wide range of readers; speech methods of presenting factual information are fascinating and quite science-intensive.

\section{Materials and method}

The purpose of this work is to identify and consider speech ways of actualizing scientific knowledge as a tool for influencing the reader's consciousness in order to increase the audience's interest in the presented knowledge in the aspect of popular science discourse and to describe the influencing potential of these speech ways of presenting knowledge. As a material for analysis, the texts of popular science articles in the amount of 200 units are offered. The analyzed material was selected by the method of continuous sampling from special popular science magazines "Machines and Mechanisms", "Quantum", "Sky", 
"Dilettante" for the period 2020-2021., which presents materials from narrow ("Quantum"," Sky"," Dilettante") and broad ("Machines and Mechanisms") fields of scientific knowledge. The popular science magazine "Machines and Mechanisms" has been published with the support of the St. Petersburg Foundation for Scientific Research of the XXI Century since 2005. Camilla Andreeva). On the pages of this publication, articles are published about the latest scientific trends, the latest inventions, technologies and communications, cars, military equipment and issues of social development. The key word in the 17 categories presented is "mechanism". Soviet and Russian popular science magazine for students, designed for the general reader. This publication has been in existence since 1970, and since 2010 it has been published with the support of the Steklov Mathematical Institute of the Russian Academy of Sciences (Chief editor, corresponding member. RAS A. A. Gaifullin). The electronic magazine "Nebosvod" for astronomy lovers publishes articles by famous astronomers and ordinary astronomy lovers. Russian educational historical magazine for the whole family "Diletant" is published with the support of LLC "Education of the 21 st century" since 2011. the volume of 96 pages (ch. ed. Alexey Venediktov). All the presented publications are published once a month.

The methodology of the presented scientific research is based on research on changes in the media sphere (convergent journalism), updates of information presentation formats, transformation of genre and style [7-10]; on the principles of popularization of science at the present stage [11]; on the principles of epistemic modality, evidentiality [12] and author's responsibility, in particular, of the addressee-scientist/ addressee-researcher, scientist $[13,14]$.

\section{Results}

The heterogeneity of the thematic content of popular science media sources dictates a certain communicative and pragmatic attitude, which undoubtedly influences the choice of speech methods that determine the implementation of the key-informing strategy of popular science discourse. In media sources, the addressee can act as a specialist in a particular field of knowledge, or a scientist, or a journalist-as a specialist who stylistically processes the abstract material with reference to the corresponding source of information in accordance with the discursive requirements. Anyway, due to its functional purpose, the declared discourse requires the addressee to present the material in such a way that it can attract the addressee from the first lines and keep him from the moment until the final line of the presented material. The implementation of certain speech methods (communicative strategies and tactics) of presenting scientific knowledge is possible due to the specific nature of the "addressee - addressee"relationship. Let's consider these speech methods in detail.

Thus, the informing strategy is implemented at the expense of certain language tools and speech techniques that mark tests of scientific and popular science style. The speech technique "prepared reader, specialist reader" - assumes that the addressee has special knowledge sufficient for the perception of the proposed text. As a rule, such texts actively use special terms without explanations and definitions. Cf.: "Planck's solution was based on the assumption that the energy of a physical system is quantized (Quantum, 2021); "...sets of helmets and tracking devices when connected to computers or game consoles allow users to interact with game worlds using ... the movements of controllers" (Machines and Mechanisms, 2020); "Eclipse-double with spherical or slightly ellipsoid components; light curves allow you to record the moments of the beginning and end of eclipses" (Firmament, 2021, No. 5). This technique is closely related to the speech method, which assumes a reader who is ready and willing to perceive complex texts. 
The rhetorical device "reader-intellectual", which assumes such an addressee who has the skills to read and perceive complex syntactically structured scientific texts (The frequency of use of syntactic constructions with a non-union connection and homogeneous series). Cf.: "Imagine, however, that we were able to make a microscope using electromagnetic radiation of a shorter wavelength: X-ray or even gamma radiation, the wavelength of which is less than $0.01 \mathrm{~nm}$." (Kvant, 2021); "Therefore, virtual reality has become most popular in video games - sets of helmets and tracking devices when connected to computers or game consoles allow users to interact with game worlds by turning their heads and moving controllers" (Machines and Mechanisms, 2021) "Eclipsedouble with spherical or slightly ellipsoid components; light curves allow you to record the moments of the beginning and end of eclipses" (Firmament, 2021, No. 5); "The data vary quite a lot, but the following figures are officially recognized: France lost about two hundred thousand people, Great Britain - about four hundred and twenty thousand, Germany - three hundred and thirty-six thousand" (Dilettante, 2021, No. 065). It is worth noting that due to the specifics of the humanitarian field of knowledge and the facts presented in the historical journal "Dilettante", non - union complex sentences are poorly represented, if there are complex constructions, then with a subordinate type of connection, in the vast majority-these are, as a rule, simple complicated constructions. Note that the speech technique "reader-intellectual" involves the use of the tactic of "appeal to background knowledge".

The tactic of "appealing to background knowledge" is implemented by using metatext markers in texts. For example: "But we know that it does not fall - the hydrogen atom is stable (Kvant, 2021); "It is worth recalling that of the biomass of one tree, $70 \%$ is accounted for by the trunk, $8 \%$ is occupied by branches, twigs, foliage/needles, $9 \%$ - bark, $13 \%$ - stump and roots" (Machines and Mechanisms, 2021, No. 5); "It is known that the tree stopped growing due to the fact that woodpeckers damaged its trunk at the top" (Machines and Mechanisms, 2021, No. 5); the brilliance of eclipsed-binary stars has been known for many centuries "(Firmament, 2021, No. 5); "Recall that Sakharov warned about "omissions" in his stories related to secrecy"; "As you know, the Soviet intelligence agencies were able to get hold of the drawings and diagrams of the first American atomic bomb" (Dilettante, 2021, No. 065). If the addressee is not sure that the addressee has background knowledge and in order to align the pragmatic presuppositions "addressee addressee", the speech method of deciphering the actual information is used. For example: "But this determinism inherent in the macroscopic world ceases to operate on the atomic scale. Let's explain why this happens... " (Kvant, 2021).

Tactics of attracting attention, or "focus of attention of the addressee" (introductory part of the text: announcement, lead paragraph) Cf.: "The year 1900, which marks the beginning of the XX century, is also the date of the emergence of quantum mechanics. It was then that Max Planck found the final solution to the problem of thermal radiation of bodies posed by Gustav Kirchhoff four decades earlier" (Quantum). "Experts distinguish three types of reality: VR, or virtual reality, AR, or additional reality, and MR-it is also mixed. Their difference is in the difference in approaches to the interaction of users and the virtual and real world...(and then the application of these realities in work, in everyday life, for entertainment, etc.) (Machines and Mechanisms, 2021); "The key circumstance for a scientific breakthrough in research on the possibility of creating super-powerful nuclear weapons was the idea called "Sakharov puff "'" (Dilettante, 2021, No. 065). In popular science texts of mass publications, this tactic is often implemented in the introductory part of the article through the use of special lexical and grammatical means (marker words "unique", "new", "for the first time", "refute the error" and others; forms of comparative and superlative adjectives (super-powerful, for example); hyperbolization, etc.). Cf.: "The" children's " example of the fourth geodesic on the surface of an ellipsoid refutes the largest 
misconception associated with the Poincare hypothesis (Quantum, 2021); "So, in one of the most striking and breakthrough exclusives of 2020, the game Half Life: Alyx, the player put on a helmet and "dressed up" in his character...according to journalists, Half Life: Alyx became a product that maximizes the gaming potential of existing technologies" (Machines and Mechanisms, 2021, No. 3); "Giant galaxies of low surface brightness - unique star systems with disks many times longer than the disk of our Milky Way, was discovered more than 30 years ago" (Firmament, 2021, No. 5). In media sources, as a rule, this tactic is implemented through certain linguistic means-markers in order to present significant scientific discoveries, facts that have the prospect of practical application.

Speech methods (strategies, tactics, techniques) of representing specialized scientific knowledge in popular scientific journals of narrow-and wide-specialized ones give reason to speak of the "addressee-addressee" relationship as a "professional-professional" interaction, which is undoubtedly dictated by the key intention of the addressee - providing the scientific information of interest to the addressee, since the addressee himself is already motivated to obtain scientific knowledge and has certain background knowledge. Based on this, we can say that in these popular science publications there are intra-scientific and international methods of presenting the knowledge of interest. The intra-scientific approach is aimed at presenting the addressee with scientific knowledge that goes beyond their highly specialized interests within a particular field of scientific knowledge, while the international approach is aimed at filling the gaps in interdisciplinary areas of scientific knowledge. In other cases, in widely specialized media sources, the purpose of which is not so much to provide strictly and highly scientific material, but to maintain its competitiveness and the desire to" hook " the casual reader, the tactics of explanation/explanation/clarification are used.

The speech tactics of explanation/explanation/explanation can be presented explicitly and implicitly. The implicit method is as unobtrusive as possible in its effect on the reader, and is correspondingly more effective [15]. The implicit method of implementing this tactic involves the use of techniques of parceling and extended repetition. Let's take an example: "We considered the situation that is now called quantum "entanglement". There is no longer one object involved, as in the Schrödenger paradox, but two. For example, take a cat and a dog, although the original wording did not suggest them. Let's assume that one of the animals is dead (which one is unknown), and the other is alive. The state in which the cat is alive and the dog is dead is $\mid+-)$, and the state in which the cat is dead and the dog is alive is/ -+). If these two states are mixed, they are said to be entangled." (Kvant, 2021); "A year earlier, in March 1923, when it became impossible to hide Lenin's illness and the systematic publication of bulletins about his health status began, the OGPU sent a special circular letter to the local party and Soviet bodies, to the command of military units" (Diletant, 2021, No. 065). Cf. (explicit expression) " the laser light is mixed with the second half of the beam. Together, they create a pattern called an interference stripe. That is, in the process of creating a program, two waves are added together - the reference and object waves" (Machines and Mechanisms, 2021, No. 3); " What do such mergers lead to? In most cases - to the destruction of disks. That is, when we are talking about such massive star systems, we do not expect to see a huge rotating disk, but rather a spheroid-an elliptical galaxy"; "The concept of "quasicrystal" ("something like") was introduced in the 1980s. It denotes minerals with an unusual internal structure" (Firmament, 2021, No. 5).

The "question-answer" tactic demonstrates a model of dialogical interaction between a layman and a professional. Let's illustrate with the following example: So what should I do? Change the strategy and cancel the point in space where the electron is detected, then another point - the result of a similar measurement with another electron, and repeat this procedure many times. (Kvant, 2021); " Sometimes it seems that for another year or two we will be able to ignore it, and then we will take everything, and we will be transported there, 
not caring about the gray and boring real world. And what will it take?... most often, only glasses are enough to dive into reality... "(Machines and Mechanisms, 2021, No. 3); " What do such mergers lead to? In most cases - to the destruction of the disks" (Firmament, 2021, No. 5).

Tactics switching the language code (paraphrasing). First, the information is presented as an academic scientific or educational-scientific text, then the same information is presented in a publicly available language form by using metaphors and comparisons. The explicit representation of this tactic implies a broad use of metatext markers (for example, in other words, in other words, and others)). We offer the following examples: "If you can measure its velocity with an accuracy of $v v$, then its position $\mathrm{x}$ is impossible to determine with an accuracy of $\Delta \mathrm{x}$ higher than $\mathrm{h} /(\mathrm{m} \Delta \mathrm{v})$, where $\mathrm{h}=\mathrm{h} /(2 \pi)$. (The constant $\hbar$ is also called Planck's constant.) In other words, $\mathrm{m} \Delta \mathrm{x} \Delta v \geq \geq$ " (Kvant, 2021);" Yes, huge losses, but, to use the cynical language of geopolitics, and a decent reward " (Dilettante, 2021, No. 065).

Speech technique of analogy (comparison and metaphor). Illustration: The marks we have placed together resemble a cloud, just as water droplets form clouds of different densities in the sky. Such an "electron cloud" is a more accurate representation of the electron than a small planet orbiting the nucleus, as depicted by Rutherford. (Kvant, 2021); " there are 32 satellites orbiting the Earth, constantly sending data to receivers: smartphones, navigators, ATMs, and a bunch of other things. You can think of satellites as a radio that transmits its music in the form of signals to each of us" (Machines and Mechanisms, 2021, No. 5). It is worth noting that the effectiveness of this technique is determined by how well the object of comparison is known to the addressee. In popular science texts presented in mass media sources, the object of comparison is the realities that are in the sphere of everyday knowledge. in the media sources proposed for analysis, the technique of analogy is widely used - visualization "through the eyes of an uninitiated reader" - the subject of speech is presented as it would be seen by the addressee himself. In this case, the author of a popular science text often has to refer to the press positions placed in the everyday, rather than scientific, experience of the addressee.

The data of the practical analyzed material for 4 journals were summarized in Table 2.

Table 1. Evaluation of the criteria for the representation of scientific knowledge in popular science journals by respondents (students of 1-2 courses of DSTU technical training areas).

\begin{tabular}{|c|c|c|c|c|c|}
\hline $\begin{array}{c}\text { Criteria for the representation } \\
\text { of scientific knowledge in } \\
\text { popular science journals }\end{array}$ & \multicolumn{3}{|c|}{$\begin{array}{r}\text { Evaluation of criteria indicators of popular science journals by respondents } \\
\text { (students of 1-2 courses of DSTU technical areas of training) } \\
\text { (according to a five-point scale) }\end{array}$} \\
\hline $\begin{array}{r}\text { № } \\
\text { ח/ }\end{array}$ & \multicolumn{2}{|c|}{$\begin{array}{c}\text { "Kvant", } \\
\mathbf{2 0 2 1}\end{array}$} & $\begin{array}{c}\text { "Machines and } \\
\text { mechanisms", 2021 }\end{array}$ & $\begin{array}{c}\text { Firmament", } \\
\mathbf{2 0 2 1}\end{array}$ & "Dilettante", 2021 \\
\hline 1 & $\begin{array}{c}\text { Informative content/ } \\
\text { knowledge intensity of the } \\
\text { proposed material }\end{array}$ & 4,9 & 4,5 & 4,1 & 3,8 \\
\hline 2 & $\begin{array}{c}\text { Dialogic nature of the } \\
\text { narrative }\end{array}$ & 4,6 & 4,7 & 5 & 4,9 \\
\hline 3 & $\begin{array}{c}\text { Relevance of the submitted } \\
\text { material, focus on a wide } \\
\text { and enthusiastic audience }\end{array}$ & 4,7 & 4,8 & 4 & 4,2 \\
\hline 4 & $\begin{array}{c}\text { The presence of a lead } \\
\text { paragraph. Applying the } \\
\text { "hook" technique in the lead } \\
\text { paragraph }\end{array}$ & 4,4 & 4,6 & 4 & 4,5 \\
\hline 5 & $\begin{array}{c}\text { Explanation/explanation, } \\
\text { explanation. Paraphrasing }\end{array}$ & 5 & 4,9 & 4,6 & 4,1 \\
\hline 6 & $\begin{array}{c}\text { The imagery of scientific } \\
\text { language }\end{array}$ & 4,7 & 4,8 & 4 & 3,7 \\
\hline
\end{tabular}


Table 2. Comparative analysis of the frequency of speech methods of representation of scientific knowledge in popular scientific journals "Kvant", "Machines and mechanisms", "Sky", "Dilettante".

\begin{tabular}{|c|c|c|c|c|}
\hline $\begin{array}{c}\text { Speech methods of } \\
\text { representation of scientific } \\
\text { knowledge }\end{array}$ & \multicolumn{4}{|c|}{ Analyzed popular science journals (electronic versions) } \\
\hline & $\begin{array}{c}\text { "Kvant", } \\
\mathbf{2 0 2 1}\end{array}$ & $\begin{array}{c}\text { "Machines and } \\
\text { mechanisms", } \\
\mathbf{2 0 2 1}\end{array}$ & $\begin{array}{c}\text { "The } \\
\text { Firmament", } \\
\mathbf{2 0 2 1}\end{array}$ & $\begin{array}{c}\text { "Dilettante", } \\
\mathbf{2 0 2 1}\end{array}$ \\
\hline $\begin{array}{c}\text { Speech technique "prepared } \\
\text { reader, specialist reader" }\end{array}$ & $15,2 \%$ & $10,1 \%$ & $13,8 \%$ & $0,2 \%$ \\
\hline $\begin{array}{c}\text { Speech technique "reader- } \\
\text { intellectual" }\end{array}$ & $12,8 \%$ & $15 \%$ & $9,1 \%$ & $11 \%$ \\
\hline $\begin{array}{c}\text { Tactic "appeal to background } \\
\text { knowledge" }\end{array}$ & $13 \%$ & $11 \%$ & $7,8 \%$ & $11,3 \%$ \\
\hline $\begin{array}{c}\text { The tactic of attracting } \\
\text { attention, or "focus of } \\
\text { attention of the addressee" }\end{array}$ & $19 \%$ & $20,1 \%$ & $15,6 \%$ & $23,4 \%$ \\
\hline $\begin{array}{c}\text { Intra-scientific and inter- } \\
\text { scientific speech reception }\end{array}$ & $9 \%$ & $8,7 \%$ & $8 \%$ & $9 \%$ \\
\hline $\begin{array}{c}\text { Speech tactics } \\
\text { explanations/explanations/ } \\
\text { explanations }\end{array}$ & $12,4 \%$ & $12,5 \%$ & $13 \%$ & $11 \%$ \\
\hline $\begin{array}{c}\text { Question-and-answer speech } \\
\text { tactics }\end{array}$ & $9 \%$ & $9 \%$ & $26,1 \%$ & $24,2 \%$ \\
\hline $\begin{array}{c}\text { Speech reception "switching } \\
\text { the language code» }\end{array}$ & $7,6 \%$ & $8,2 \%$ & $6,6 \%$ & $9,7 \%$ \\
\hline $\begin{array}{c}\text { Speech technique of } \\
\text { "analogy" }\end{array}$ & $2 \%$ & $5,4 \%$ & $0,2 \%$ \\
\hline
\end{tabular}

\section{Conclusion}

As a result of the preliminary survey of respondents (students of academic groups), it turned out that according to 6 criteria, according to which the articles of 4 journals were evaluated, the most interesting for student groups is the journal "Quantum", which has a narrow scientific focus (physics and mathematics). No less interesting for them was the magazine "Machines and Mechanisms", which in 17 headings, through the intra-scientific and inter-scientific component, shows the mechanism of the phenomenon in various branches of knowledge. This fact was interesting and very convincing for the students.

The results of the survey and the methodological basis of this study allowed us to identify the most key speech methods (techniques and tactics) of presenting scientific knowledge, namely: the speech technique "prepared reader, reader-specialist"; the technique "reader-intellectual"; speech tactics "appeal to background knowledge"; tactics of attracting attention, or "focus of attention of the addressee"; intra-scientific and interscientific speech techniques; speech tactics of explanation/explanation/explanation, paraphrasing; tactics "question-answer"; speech technique "switching language code"; the "analogy"technique. By using quantitative and qualitative methods and the method of description, it was possible to find the corresponding analyzed examples, which allowed us 
to identify the most effective and frequent speech ways of representing scientific knowledge.

The study shows that the speech techniques "prepared reader, reader-specialist" and "reader-intellectual" were represented as much as possible in the magazines "Quantum" and "Machines and Mechanisms", which is quite comparable with the respondents ' high assessment of such an indicator as the informative content/ knowledge intensity of the proposed material, which is due to the stylistics of the presented text: the presence of terms and complex syntactic constructions. The demanding reader is ready to receive knowledgeintensive information "with interest", making maximum efforts, which contributes to the formation of the reader's taste. The speech tactic "appeal to background knowledge" is also somewhat higher represented in these journals. The tactics of attracting attention, or "focus of attention of the addressee" are more clearly presented in the magazines "Machines and mechanisms "and" Dilettante", which corresponds to the evaluated criterion - the presence of a lead paragraph and the use of the" hook " technique in the lead paragraph. An important role in updating and attracting the attention of the audience, or rather its retention, is played by the speech tactics of explanation/explanation/explanation, paraphrasing, which is less represented in the historical magazine "Dilettante", which corresponds to the respondents ' assessment. The criterion of dialogic narration is the most desirable for respondents, which is embodied in the speech tactics of "question-answer". This technique is actively used on their pages by the magazines "Dilettante" and "Sky", which helps to keep the reader throughout the story. It is worth noting, however, that, as a rule, this technique is a favorite because of the specificity of knowledge - humanitarian and astronomical, as in this case. One of the specific criteria for a scientific and popular science text is the imagery of the scientific / popular science language, which is not so familiar, peculiar and not so active in the use of this type of text, but nevertheless was presented in a higher percentage in the magazines "Machines and Mechanisms", which is quite understandable for its intra-scientific and international scientific component, and in the magazine "Quantum", which is least characteristic of the historical magazine "Dilettante".

Based on the data obtained from the survey and the study of practical material, the influencing potential of the studied speech ways of presenting scientific knowledge to the addressee occurs along the path: title (rhetorical question; the use of a named syntactic construction, often with the use of an oxymoron or antithesis) $\rightarrow$ the presence of a lead paragraph (the "hook" technique, the "focus of attention of the addressee" technique) $\leftrightarrow$ informative content (the "prepared reader, specialist reader", "intellectual reader" technique» - the use of terminology and simple or complex non-union constructions) $\leftrightarrow$ the moment of explanation and reference to background knowledge (tactics of "appeal to background knowledge" and explanations/explanations/explanations) $\leftrightarrow$ paraphrasing (the technique of " switching the language code») dialogic storytelling (question-and-answer tactics») the imagery of the scientific language (the technique of "analogy" through the use of comparisons and metaphors). That is, a compositionally well-constructed text increases the chances of reading it. An attractive title, the presence of a lead paragraph, a knowledgeintensive content part, which competently combines speech tactics and methods of presenting information with a kind of imagery of scientific language, an explanatory manner of narration, and, finally, a concise conclusion. This is the rhetorical canon of the modern popular science text.

The "image of the addressee", an enthusiastic intellectual reader, is largely modeled by the addressee himself, which is determined by many factors, for example: the type of media source in which the popular science text is published; the set of speech strategies and techniques used by the addressee himself; awareness in a certain area, erudition of the author, his language capabilities and creative abilities. 


\section{References}

1. P. N. Demchenko, I.V. Maltsev, Nauchny Dialog, 3, 171-189 (2021), doi: 10.24224/2227-1295-2021-3-171-189

2. T. V. Shchukina, S. G. Voskoboynikov, A. V. Babaytsev, I. V. Topchiy, International Journal of Criminology and Sociology, 9, 1972-1978 (2020)

3. D. Y. Shalkov, V. V. Kolmakova, E. S. Shilova, Modern Global Economic System: Evolutional Development vs. Revolutionary Leap, 136-144 (2021)

4. E. V. Osipov, Z. M. Nalgieva, M. M. Batyushin, M. I. Nazheva, I. I. Anufriev, Cardiovascular Therapy and Prevention, 1, 61-62 (2021)

5. E. V. Kharlamov, S. V. Orlova, O. V. Doycheva, E. V. Osipov, Sports Medicine: Science and Practice, 7(2), 78-83 (2017)

6. O. N. Bessarabova, E. S. Shefieva, M. P. Churikov, Engineering education and training systems for graduates of technical universities for carrying out professional activities in the leading countries of the world, 244 (2016)

7. T. A. Vorontsova, Bulletin of the Chelyabinsk State University, 6, 38-42 (2014)

8. I. V. Kovtunenko, V. A. Borisenko, S. V. Bylkova, N. A. Minakova, V. I. Rogacheva, XLinguae, 11(2), 95-105 (2018), DOI: 10.18355/XL.2018.11.02.08

9. V. Kolmakova, D. Shalkov, O. Baryshnikova, E3S Web of Conferences, 210(8), 18023 (2020), doi: 10.1051/e3sconf/202021018023

10. S. V. Bylkova, and D. Y. Shalkov, E3S Web of Conferences, 210, 18010 (2020)

11. A. A. Tertychny, Information Field of Modern Russia: Practice and Effects, 330-336 (2014)

12. E. N. Klemenova, I. A. Kudryashov, Bulletin of Novosibirsk State University. Series: History. Philology, 17(6), 97-107(2018)

13. Y. S. Kosyakova, News of the Southern Federal University, 4, 82-91 (2018)

14. S. V. Bylkova Baltic Humanitarian Journal, 7, 4(25), 21-25 (2018)

15. Y. S. Kosyakova, Bulletin of the Irkutsk State Technical University, 8 (91), 232-235 (2014) 